\title{
AMERICAN ELECTROENCEPHALOGRAPHIC SOCIETY
}

\author{
SEVENTEENTH ANNUAL MEETING \\ San Francisco, Calif., Octoher 7-9, 1963 \\ Secretary: DR. K. A. KooI \\ University of Michigan Medical Center, Ann Arbor, Mich. (U.S.A.)
}

1. Functional localization of thalamic responses to photic stimuli in the cat. - F. Torres (Minneapolis, Minn.).

Multiple thalamic connections with visual pathways have been demonstrated by both anatomical and physiological experimental methods. The present investigation was undertaken with the purpose of better defining and localizing the different types of responses elicited from thalamis nuclei by photic stimulation.

Groups of multiple vertically arranged depth electrodes were inserted bilaterally in the thalamus of cats immobilized with Flaxedil and locally anesthetized. Brief light flashes were delivered to both eyes in pairs, with increasing intervals between conditioning and test stimuli. Respontses were recorded on a multichannel magnetic tape. Series comprising between 48 and 96 responses were recorded from each pair of electrodes on a dual-beam cathode ray oscillosccpe and on two channels of a computer of average transients (CAT). Intercollicular section was performed and the series of stimulations repeated after the section. At the end of the experiment the animals were perfused with formalin. Serial sections verified the location of thalamic electrode locations. Responses were played back from the tape into the CAT for averaging and plotted with an $X \cdot Y$ recorder.

Multiphasic potentials wore obtained from specific and nonspecific thalamic nuclei. Different components of responses were functionally differentlated from each other by their changes aftor intercollicular section, by reversal of polarity between adjacent recording electrodes in various thalamic nuclei, and by their different recovery cycle as tested by double light flashes. These findings, as well as complex incuractions found to exist between different response components, will be discussed.

(Supported by USPHS Grant M-2492, NIMH).

2. Excitation and imhibition of nucleus ventralis posteroIateralis resulting from cortical stimulation. $-\mathbf{D}$. Garoutte, H. Shlmaza and N. Yanagianwa (Tolyo, Japan).

The effect of electrical stimulation of the pericruciate cortex on individual neurons of the nucleus ventralis posterolateralis (VPL) of the thalamus was studied in cats. Unit spikes were evoked by single test shocks either to peripheral nerves or to the medial lemniscus. Recording was with glass micro-pipettes. About one third of the neurons could also be excited antidromically by single shocks to a restricted area of the postcruciate cortex. In a similar proportion, including some of the same neurons, the excitation was post-synaptic. Some were also excited by antidromic stimulation of the ipsilateral pyramid at the ponto-medullary border. This pyramidal stimulation produced only small "a" and "beta" resporses (Jabbur and Towe) in the lateral part of the postcruciate gyrus.

When the cortex adjacent to the aforementioned restricted area of cortex was stimulated prior to the medial lemniscal test stimulation, the VPL unit was commonly inhibited; i.e., its latency was increased, and the number of unit spikes per test stimulus was usually decreased. This inhibitory effect began within 20 msec after the conditioning cortical stimulus, and sometimes lasted as long as $300 \mathrm{msec}$, or even longer. Following cortical ablation, with degeneration of the descending pyramidal fibers, stimulation of the exposed white matter had an antidromic inhibitory effect on the VPL neurons.

These effects may result from local excitation of VPL neurons by pyramidal efferents, with inhibition of surrounding VPL neurons. The inhibition is probably via recurrent fibers from the excited neurons, and may operate functionally in "sharyening" incoming sensory impulses.

\section{Longitudinal electrographic correlation of avoldance behavior, - J. A. Wada and 11. Kumashlro (Vancou- ver, B. C., Conada).}

The present study stems from our earlier observations of chronic epileptic cats which survived more than 3.5 to 4 years after being made epileptic. In a simple avoidance situation, they were found to be extremely poor in learning this simple performance compared with normal cats similarly tested. In order to investigate the significance of such impaired learning in a chronic epileptic state, an investigation of electrographic correlation of avoidance was initiated 3 years ago. Seventeen cats were prepared: six normal controls, five with destructive lesiolis, and six with epileptic lesions. The site of lesion was the medioinferior temporal region. Concentric electrodes were implanted in the following structures: optic tract, lateral geniculate, superior colliculus, visual cortex, lateralis posterior, pulvinar, midbrain reticular formation, putamen, caudate, hippocampus, and amygdala. They were followed in the process of habituation, conditioning, extinction and re-conditioning. The CS was $1 /$ sec flickering light, and the US was an electric shock to the feet of the animals. Electrical evoked responses by the CS were recorded during this behavioral process. In order to evaluate the modulating role of pupil size on the central evoked response, the $\mathrm{CS}$ was delivered through either 
normal intact or atropinized maximally dilated pupil of the same animal on alternate days. Respiratory rate, ECG, retinal potential and EEG with automatic frequency analysis were simultaneously recorded. At the conclusion of this study all the animals were sacrificed, and the localization of surgical lesions and electrode sites was histologically verified.

Characteristics of the evoked potential appeared to vary greatly in the same organism even within a short span of time. Consequently, only constantly identifiable response components with measurable amplitude were subjected to statistical longitudinal evaluation. The daily computed mean evoked response amplitude became the basis of charting the longitudinal pattern for each recording site. The common denominator findings in the control group were: (1) remarkable, though not complete, degree of similarity and parallelism between the longitudinal patterns derived through either dilated fixed pupil or intact pupil, (2) relative independence of chronological patterns among retinal and more centrally recorded potentials in the same animal, and (3) gradual alteration either in the direction of increase or decrease during both habituation and conditioning, with abrupt and marked fuctuation in the early conditioning period.

Difficulty was encountered in finding a significant group difference in the longitudinal patterns. This is probably due to the sufficiently complex and diverse nature of control patterns, in addition to an insensitive sampling method with its inherent limitations. We have evidence that a group difference indeed exists in the form of an unstuble, large, later response component of about $\mathbf{2 0 0}$ msec peak latency in the destructive lesion group.

Although all three groups achieved high behavioral score in terms of avoidance performance, evidence was found suggesting that the presence of a temporal lobo lesion, regardless of its nature, made adaptation of these animals to a stressful avoidance situation more difflcult.

\section{Direet eurrent recording and stlmulation during learn. ine In rabbits. - T. PintorHamuy, F. Proctor and 1. Kupferman (Palo Alto, Calle).}

Twenty-two rabbits wero trained to perform a conditioned avoidance response to a buzzer. During training, RC coupled and DC recordings were made from nonpolarizable electrodes implanted in frontal, visual and auditory cortex bilaterally. The effect of cathodal and anodal polarization at early (less than $80 \%$ conditioned responses) and late (more thatı $80 \%$ conditioned responses) was tested. Cathodal polarization in auditory cortex during conditioning trials lowered performance particularly in early stages of training. Results with cathodal polarization in frontal cortex were more variable, but also tended to lower performance. Anodal polarization in either audit?ry or frontal cortex increased performance slightly or liad no effect.

DC shifts in response to the conditioned stimulus were in a positive direction. In general, the frequency of occurrence and magnitude of the DC shift decreased through the course of training. In a few animals there was a correlation. between the DC shifts and the level of performance.

\section{Influence of slow changes in the EEG on the firing rate of cortical neurons. - G.H. Fromm and H. W. Bond (New Orleans, La.).}

Simultaneous recordings from single neurons in the suprasylvian gyrus of the cat and of the electrocorticogram, recorded with DC amplifiers, were obtained. The cortex was found to be slightly negative ( -1.15 to $-3.10 \mathrm{mV}$ ) relative to a reference electrode in the frontal sinus. As long as the animal remained in good condition this potential difference was constant throughout the recording (up to $5.5 \mathrm{~h}$ ), with fluctuations of 0.1 to $0.5 \mathrm{mV}$ lasting 0.5 to 5.0 sec. Cortical neuron activity appeared to be related to these potential changes. They tended to fire faster during positive waves and slower during negative ones. These results are discussed relative to the theory that dendrites respond on a more-or-less rather than allor-none basis, and that they modulate the firing rate of the neuron's soma by means of the electrotonic fields their activity creates. (Full paper in press in this Journal).

\section{6. "Excitabllity cycle" of dendrites as determined by a technique of minimal stimulation and response-averag. Ing. - J. K. Merlis (Baltimore, Md.).}

It has been suggested that some of the spontaneous rhythms of the EEO are related to the excitability cycle of dendrites, but the literature on such cycles contains many inconsistencies. Our previous studies have indicated that some of the discrepancies in data are attributable to the stimulus intensities required by the usual methods of ovoking and recording tho superfleial or direct cortical response. The present study demonstrates that a much more conslstent pattern of responsiveness emerges when very weak stimuli are employed.

Brief $(50 \mu \mathrm{sec})$ square pulses at intensities of the order of $45=70 \mu \mathrm{A}$ were applied through closely spaced elec. trodes (Ringer-filled capiliaries, $\mathbf{0 . 6} \mathrm{mm}$ between centers) to the cortex of succinylcholine-paralyzed cats. Recording was accomplished by means of the CAT averager of evoked potentials. Responsiveness was tested by the paired shock technique, the test shock being applied at intervals of 1 to 250 msec after the conditioning shock. The stimulus pairs wore applied every 1 to 2 sec, and a minimum of 120 responses was averaged for each interval.

Under these conditions, there is a consistent period of summation at stimulus intervals up to $5-6.3 \mathrm{msec}$, followed by a period of depression which is very variable in duration. Increasing the stimulus intensity to values of the order of 100-140 MA consistently shortens the period of summation, depression becoming evident at about $4 \mathrm{msec}$. Preliminary data indicate that Nembutal anesthesia reverses this effect of increased stimulus current.

The data obtained suggest that the long duràtion "excitability cycle" of dendrites reported by others is not an intrinsic phenomenon of the dendrites but is a consequence of synaptic mechanisms initiated by the dendritic activation. 
7. Effects of lidocaine upon spontaneous and evoked activity within the limbic system, - I. H. Wagman, R. H. de Jong and D. Prince (San Francisco, Calif, and Palo Alto, Calif.).

Studies were made of the effects of intravenous lidocaine on (1) spontaneous electrical activity of surface and depth loci in both acute unanesthetized cats and chronically implanted cats and rabbits, and (2) evoked potentials recorded oscillographically. In chronic preparations small doses $(5-8 \mathrm{mg} / \mathrm{kg})$ of lidocaine induced hyperventilation and bursts, synchronous with respiration and dependent upon airflow through the nostril, of 15-18/sec spindle activity in corticomedian and central amygdala. These spindle bursts were not seen before drug administration. Spindles of lower amplitude were seen at other amygdaloid points, septum and pyriform cortex, but not usually in hippocampus. Nonlimbic structures, including various specific and nonspecific thalamic nuclei and midbrain and bulbar tegmentum, showed no alteration in their spontaneous activity during this spindling. Within $1 \mathrm{~min}$ after onset of spindling, surface activity was slow and the animal appeared drowsy. With higher doses (>10 mg/kg) rhythmic amygdaloid activity changed to rhythmic spiking or spike-spindle complexes also related to respiration. Frequently, high voltage spike discharges, independent of respiration and accompanied by behavioral seizure, began in umygdala and spread to other depth and surface areas. Postictal depression of amygdaloid activity followed. Lidocaine, even in small doses $(5 \mathrm{mg} / \mathrm{kg}$ ), transiently blocked potentials in prepyriform cortex and amygdala evcked by olfactory bulb stimulation. However, it did not block specific thalamocortical evoked potentials. It is postulated that lidocaine has an excitatory influence on amygdala independent of its effects on respiration. This may occur through block of systems which normally inhibit amygdaloid activity rather than by directly aflecting amygdala.

(Supported by USPHS Grants 624604-11, 26-63(C4) and GM-08013, NIH).

8. Central and peripheral factors In eplleptic discharge: experimental studies in the cat. - J. R. Stevens, Y. Nakamura, V, Milstein, T. Okuma and R. Llinas (Portland, Ore, and Boston, Mass.).

The influence of certain brain-stem structures on experimental epilepsy in the cat was investigated in the following manner: 3 weeks to 6 month following inoculation of cerebral cortex with alumina gel, electrocoagulation of a variety of midbrain structures was accomplished by means of previously placed depth electrodes. Effects of these lesions on behavior, neurological status, spontaneous seizure activity, electrocorticogram and seizure threshold to photic stimulation were examined. Studies of afterdischarge threshold at the site of the epileptogenic lesion, the "homotopic focus", and distant cortical areas were made in the unrestrained waking animal before and after the midbrain destructions by means of chronic cortical electrodes.

In addition to the marked changes in behavior and neurological status following such lesions, there was frequent appearance of synchronous high voltage spikewave type of response to photic stimulation following the brain-stem lesions. Analysis of the change in seizure threshold, electrocorticogram and other variables examined will be discussed in relation to the lesions in the brain-stem of these animals.

\section{Interamygdaloid propagation. - O. J. Andy, J. Mukawa and J. Melvin (Jackson, Miss.).}

The problem was to ascertain whether amygdala afterdischarges preferentially propagate to the opposite amygdala by way of one or more of the following: (1) anterior commissure, (2) ipsilateral temporal cortex, (3) hippocampal commissure and (4) basal telencephalic structures. Seventeen immobilized cats were operated upon under local anesthesia. Bipolar electrical stimulation and recordings were made with a Grass stimulator and Grass electroencephalograph, respectively. Stimulation parameters: $1 \mathrm{msec}$ pulse, $50 \mathrm{c} / \mathrm{sec}, 5 \mathrm{sec}$ duration, voltages of 1 to 1.5 above the discharge thresholds. The effect of lesions upon the propagated discharge amplitudes was evaluated as follows: (1) complete interruption, voltage drop to zero from $200 \mu \mathrm{V}$ or greater, (2) partial interruption, a voltage drop of $200 \mu \mathrm{V}$ or greater, but not to zero, and (3) no interruption, voltage drop of less than $20 \mu \mathrm{V}$. A minimum of two stimulations in each amygdala was done before and after each lesion. After-discharge voltages recorded from the stimulated sites were unchanged following the lesions.

Lesions of the temporal, motor, parietal and occipital cortices, the posterior hippocampus and anterior commissure did not reduce the amplitude of the propagated discharges. Lesions up to $3 \mathrm{~mm}$ ill diameter in the anterior amygdaloid and preoptic area did not reduce the amplitudes, whereas larger lesions did. Several lesions were mado with a sucker advanced caudoventrally through the anterior sigmoid gyrus. In these, amplitude reduction, if present, occurred when the preoptic or the anterior amygdaloid area was encountered. In only three animals was there complete interruption of the propagated dis. charge.

Conclusions: Ablation of the temporal and other cortical areas, the posterior hippocampus and the anterior commissure did not interrupt nor significantly reduce the amplitude of interamygdaloid propagated discharges. Propagation may be reduced or interrupted by relatively large lesions placed in the basal telencephalic structures.

\section{Long duration cyclical changes in excitabllity of spike} focl. - D. Prince (Palo Alto, Calif.).

Studies of the behavior and excitability of penicillin spike foci in visual and auditory cortex were performed in unanesthetized gallamine immobilized or encéphale isolé cats, EEG inkwriter ind CRO records of spontaneous and driven spike discharges were made under a variety of conditions.

When the appropriate stimulus (flash or click) was presented at low frequencies $(1-6 / \mathrm{sec})$ for many minutes, cycles of spike driving alternating with periods without spike driving were observed. Thus, a continuous $4 / \mathrm{sec}$ flash might induce $2 \mathrm{c} / \mathrm{sec}$ driving of a visual spike focus 
for periods of 15 to $25 \mathrm{sec}$, alternating with periods of is to $25 \mathrm{sec}$ when only the evoked response to light was seen. The most striking feature of these observations was the similar duration and configuration of successive spike cycles. Twenty or more consecutive cycles were commonly observed. Spike cycles could be interrupted by stopping the driving stimulus but were unaffected by high frequency tegmental shocks. Intercollicular section did not prevent the development of cycling, nor did pentobarbital administration, or recording in a dark room with fixed pupils in the case of visual foci. Such regular cyclical variations were not observed in spontaneously firing foci in intact or chronically isolated cortex.

To our knowledge, cyclical changes in excitability of this duration have not been previously described. These findings are difficult to explain in terms of the known behavior of neuronal systems and may represent periodic inhibition originating within the focus or in a subcortical neuronal organization.

\section{Bllateral "epileptogenic" focl in cat cerebral cortex: machanisms of interaction in the intact, the bllateral cortical-callosal and adiencephalle preparation, - E.M. Mareus and C. W. Wateon (Boston, Mass.).}

We have studied the relative roles of corpus callosum and diencephalon in determining patterns of electrical discharge resulting from the interaction of epileptogenic foci produced by bilateral application of strychnine, Metrazol and conjugated estrogen to corebral cortex. In seven animals with intact brain, immobilized with Flaxedil and artificially ventilated, there occurred a symmetrical spike discharge often synchronized within 0-12 msec, followed by prolonged symmetrical and synchronous $3 \mathrm{c} / \mathrm{sec}$ spike and wave complexes. Recordings from medial thalumus indlented insignificant participus. tion of these thalamic areas in the initial appenrance of the complexes. Section of the corpus callosum signifleantly disrupted the synchrony of the cortical discharge. In eight animals, patterns of symmetrical spikes and repeti. tive 3 e/sec spike-wave complexes, often synchronized within $2-20 \mathrm{msec}$, followed the application of convulsant agent to bilaterally isolated blocks of cortex which re. mained connected by corpus callosum.

Similar results were obtained in five unanesthetized animals following ablation of entire thalamus, hypothala. mus, rostral mesencephalon and dorsal hippocampus, and in seven animals after ablation of medial thalamus and rostral mesencephalon. Preservation of visual pathways in three of the latter group permitted precipitation of a bilateral discharge to flash stimulus following application of convulsant to visual cortex bilaterally. Relevant clinical concomitants of the simultaneously recorded synchronous contical discharges in six unrestrained animals included immobility, symmetrical facial and forelimb myoclonus and generalized convulsive seizures.

These data indicate a significant role of intracortical and transeallosal mechanisms and an insignificant role of diencephalon and rostral mesencephalon in the generation of a bilaterally symmetrical and synchronous 3 c/sec spike and wave pattern similar to that of "petit mal" in man.

\section{A technique for spectral analysis of EEG.-E. Eidelberg} and F. C. Cheshire (Phoenix, Ariz.).

Quantitative description of the EEG is often required in studies on behavior and on the effects of drugs on the CNS. Current techniques for EEG analysis in the frequency domain require the use of passive tuned filters, the use of computer filters on digitized EEG data or Fourier transformation of correlograms. The first method has poor resolution at the low end of the spectrum, the second is too e:pensive and the third enhances "dominant" frequencies and eliminates others. We are employing a lock-in amplifier as a narrow bandpass filter, whose output is a DC level proportional to the power contained in each band selected, with a variable time constant of integration. The output of this amplifier is digitized and then treated statistically. The same technique allows cross-spectral studies. It also allows longitudinal studies of variance in the relative amplitude of a narrow selected frequency band component. Another advantage of this method is that relatively inexpensive, commercially available equipment is employed throughout. The same components are used for average response and single unit studies.

(Supported by USPHS Grant B-3496, NINDB).

\section{An electronically derived frequency distribution of the human EEG. - R. Cohn (Bethesda, Md.).}

By means of an electronic amplitude discrimination system, developed at the U.S. Naval Hospital, Bethesda, precision measurements of the frequency distribution of man's EEO have been obtained in more than 70 individuals. The instrumentation consists of matched amplifiors, a dual track magnetic tape recorder, a pulse generator and the Mnemotron CAT 400A. Depending on the subject, two or three major frequency peaks are recognized. The highest amplitude is in the alpha frequency range, usually peaking ut 9 or 10 waves/sec. The low and high frequency edges of the roughly normal digtribution are usually ut the 8 and 14 wave/sec ordinate, respectively. (Inexpect. edly, two fifths of the subjects showed higher amplitude peaks over the left side in homologous derivations. A secondary peak was sometimes seen in the frequency band at around 20 waves/sec in each front. The low Irequency peak was most often observed as the first subharmonic of the fundamental frequency. The slow activity of sleep and the slow waves of pathological brain function tend to be random in frequency. The frequency distributions are reproducible under standard conditions of recording. The frequency distributions automatically obtained conform to, and confirm, measurements made by experienced electroencephalographers. In a pair of twins the frequency distribution natterns were remarkably similar. Precision frequency spectrum measurements are an important prelude to effective computer studies of the EEG.

\section{Comparative study of period analysis and frequency analysis of the electroencephalogram. $-\mathbf{N}$. Burch and M. Fink (Houston, Tex, and St. Louls, Mo.).}

In recent reviews of EEG quantification techniques, the advantages of period analysis were described. The devel- 
opment of the logic and program for period analysis, using a general purpose digital computer, has made the technique readily available and suggests the need for a comparison of data analysis by conventional electronic harmonic filter analyzer methods and period analysis.

Electroencephalograms of twenty psychiatric patients with a variety of resting records were recorded on magnetic tape. Analysis of identified portions of record for 60 sec pre-hyperventilation was undertaken, using a UlettLoeffel analyzer in St. Louis. The same records were analyzed using the Burch period analyzer in Houston. Additional samples were analyzed using the digital computer program for period analysis.

The advantages and limitations of both techniques will be described.

\section{Phase indicated organization and interchannel interac- tion following arousal. - C. W. Darrow (Chicago, ili.).}

Instrumentation providing simultaneous continuous scoring of leading and lagging and in-phase time relationships between pairs of EEGs from any six electrode placements permits observations of interarea time relations of EEG activity over the entire head. Sleep, drowsiness and disturbed states tend to be characterized by random lead-lag time relations between adjacent areas.

Increase of apparent systematic organization characterizes alerting ur arousal. With or without intervention of attenuation or "blocking", there is an increase of rhythmic activity in which the more anterior of two compared areas leads by a fraction of a cycle the more posterior, and in-phase activity may characterize homologous areas of the two sides. Rapid dipluasic interchannel interactions follow attention-getting and ideational stimuli. This may be an offect of specific local modulations of the EEG which heterodyne with otherwise identical adjacent rhythms to trigger apparent inter-area interaction.

\section{Some characteriatics of alphnuprovocation. - L. Morrell and F. Morrell (Palo Alto, Callf.).}

The present report is based upon fifteen experiments with normal young adults, all of whom presented in their resting electroencephalogram a percent time alpha exceeding $70 \%$. Under conditions of recurrent photic stimulation (habituation procedure), a decline in the duration of alpha desynchronization to the signal was observed, following a waxing and waning course. As the experiment continued, a shift in the background rhythms in the direction of slower, smaller amplitude, more random activity appeared. Against this background, the same signal which previously elicited a blocking of the alpha rhythm now provoked activity in the alpha range. These two configurations of background plus electrographic response tended to alternate during the course of a prolonged series of signal presentations. Some of the morphological features of the provoked alpha rhythm will be detailed (latency, duration, resistance to habituation, topography, amplitude, frequency). The relation- ship between alpha-provocation and reaction time and autonomic responses will be considered.

(Supportited by NASA Grant SC NsG-215-62).

17. Age difiterences in EEG response to visual stimulation. S. Wilson and W. D. Obrist (Topeka, Kan. and Durham, N. C.).

Fifteen young (18-29 years) and fifteen elderly (63-84 years) male subjects of good heaith and superior intelligence were compared with respect to the amount of EEG desynchronization produced by visual stimulation. A $75 \mathrm{~W}$ lamp, mounted 24 in from the closed eyes, was turned on $3 \mathrm{sec}$ and off $9 \mathrm{sec}$ for twenty presentations. The magnitude of the EEG response during each $3 \mathrm{sec}$ stimulus period was measured by subtracting the integrated parieto-occipital voltage from the resting control level. Adaptation curves were obtained by plotting this measure against the twenty stimulus trials.

In comparison with the young group, the elderly subjects showed significantly smaller EEG responses (voltage changes). Typical mean adaptation curves were obtained which, when plotted semi-logarithmically. revealed a linear relationship between EEG response and trials. The log curves for the two age groups were parallel; i.e., they had the same slope but different $y$-intercepts (young greater than old). This suggested a similar adaptation rate but a different response magnitude. After a brief rest period, an additional twenty stimulus trials produced almost complete adaptation in the elderly group, while the young subjects continued to show small responses. The findings were independent of initial voltage level.

The results were tentatively interpreted as evidence of reduced electrocortical reactivity in old age. The possible influence of peripheral visual factors will be discussed, along with the implication of these findings for senescent changes in mental function.

18. BEG patterns in sleep of full term and premature newborm infants, - A. H. Parmelee, Jr, Y. Aklyama, N. Monod and J. Flencher (Los Amgeles, Callf.).

According to Dreyfus-Brisac, below 32 weeks gestational age no differentiations can be made of definable stages of sleep by EEG patterns, but at term ( 40 weeks) scveral sleep states can be identified. The present study was done to see if these observations could be confirmed with the state of the infant more carefully defined by simultaneous polygraphic recording of EEG, respiration, eye movements, actogram and EKG, along with detailed observation of behavior during prolonged periods of recording.

Recordings were made continuously during a 3 h interfeeding period (9-12 AM). The following data from each 20 sec page were punched on IBM cards: heart rate, respiratory rate, respiratory pattern on a 5 point scale, number of eye movements, amount of activity recorded, observed behavior on a 10 point scale, and EEG pattern on an 11 point scale. By means of a coinputer, correlation tables for these variables were made for each record of 400-500 codable pages.

Of a larger number of babies being studied, the records 
of four babies have been analyzed in this way to date. Two babies were born at full term and are part of our control group. Their recordings were done on the 2 nd and 4 th days of life. The other two babies were born prematurely at 28 and 29 weeks of gestational age, and recordings were done at 32 weeks, 36 weeks and 40 weeks (term) of gestational age. This allowed us to follow the maturation of their EEG patterns to term and to compare their term records with those of the infants born at term.

In the term infants, the coded EEG categories correlated well with observed behavior, and defined at least three states with eyes closed and one with eyes open. The infants born prematurely were like the term infants when recorded at 40 weeks gestational age. Heart rate, respiratory rate, respiratory pattern, eye movements and actograms also correlated well with the observed behavior and EEG code. Combinations of behavior, respiratory patterns, eye movements, and heart rate defined additional states of sleep that had characteristic EEG patterns. The two infants recorded at 32 weeks of gestational age did not show EEG patterns that could clearly be related to state as observed, though there were some suggestive changes. The heart rate, respiratory rate and eye movements seemed to be unrelated to EEG patterns, but there was some correlation with respiratory patterns. These same infants recorded at 36 weeks gestation had at least two definable states with oyes closed, and one with eyes open, in terms of observed behavior and EEG code. The heart rate, respiratory rate and eye movements were also better correlated with state at this gestational age.

\section{Propertles of the photomotor response system, $-\mathbf{R}$. G. Dicteford (Rocheator, Mlan.).}

In previous studies, some of the properties of the photo. myoelonic reaponse to light stimulation have beis delin. eated using conventional recording methods. With tho introduction of averaging technics, the delection of myo. genic responses below movement threshold becomes feasible. In such studies a CAT computor has been employed to investigate the response detectable in normal subjects to high intensity light pulse stimulation. This has revealed a widespread (face, neck, arms) response system which, due to the frequent absence of visible movement, can be more appropriately called photomotor rather than photomyoclonic. Response latencies of 55 msec in the face, 60 to $80 \mathrm{msec}$ at the inion and 60 to $65 \mathrm{msec}$ in the arm have been commonly encountered. The latency increases at higher $(10 / \mathrm{sec})$ driving rates. The response is abolished by curare in paralytic doses and markedly accentuated by small (20 to $50 \mathrm{mg}$ ) doses of Metrazol given intravenously. It is usually increased by eye closing. With appropriate stimulus delays (50 msec for inion recording) between light and sound, an interesting interaction of the photomotor and sonomotor systems at the final common pathway can be demonstrated. This confirms the myogenic nature of both responses. The photomotor system is a potential contamination hazard in evoked potential observations in the human unless special precautions are taken.

(Supported by USPHS Grant B-j225, NINDB).
20. Comprison of cerebral and myogenic componetits of the averaged response to sound stimulation in man. - J. E. Walker, J. L. Jacobson and D. T. Cody Rochester, Minn.).

Recent studies (Bickford, Fed. Proc., 1963, 22: 678) have shown that short latency (6 to $8 \mathrm{msec}$ ) responses to sound stimulation recorded from the human scalp are myogenic in origin. Furthermore, the receptors invclved in this "scnometor" response belong to the vestibular rather than the cochlear system. These findings suggested a need to investigate the origin and pathways of the well known later components of the response to sound stimulation in the human. Twenty normal subjects have been studied employing a wide range of sound (ciick) intensity and with wide scalp electrode coverage (simultaneous recordings with 7 channel tape system). Responses have been averaged with the Mnemotron CAT computer, and special muscle tensing maneuvers have been used to detect myogenic components. The later components of the response to sound stimulation have been found to be maximal in the vertex region (latency of negative peak at 70-80 msec and following positive peak at 120-160 msec) and doubtlessly represent the nonspecific sensory system. In contrast to behavior of early components of the response, muscle tension produces only minor changes in amplitude and wave form. In audition, the late component system cannot be driven to the high response rates (over $100 / \mathrm{sec}$ ) which are characteristic of the sonomotor responses. Late components are, however, influenced considerably by maneuvers designed to shift the subject's attention. Further differentiation of the two response components has been achieved using patients with various types of audiovestibular lesions.

(Supported by USPHS Grant B-2056, NINIDB).

\section{Wvoked cortleal potontial correlates of attentlon in human subjecti. J. H. Satterfield and D. Cheatum (St. Louls, Mo.).}

By using a smalt special purpose digital computer, sensory evoked corticul potentials can be measured through the intact scalp in human subjects. It was the purpose of this study to ascertain whether or not the average evoked cortical potential to a shock stimulus at the wrist would be different when the subject was attending to the stimulus than when he was not attending to the stimulus.

Method: The active electrode was located over the posterior quadrant of the sealp, contralateral to the stimulus. The inactive electrode was placed on the tip of the nose. Shock stimuli were delivered alternately to the right and left wrists at 1 sec intervals. An average evoked cortical response to the stimulus to the right wrist and an average response to the stimulus to the loft wrist was built up over the same time interval. In one experimental situation the subject was given some reading to do and instructed to ignore both stimuli. In the other experimental situation the subject was instructed to attend to and count the number of stimuli delivered to one wrist and to not attend to the stimulus to the other wrist. Comparison was made of the amplitude of the average evoked cortical response when the subject was attending to the 
stimulus and when he was not attending to the stimulus.

Results: When attending to the stimulus to the right wrist, the response to that stimulus was reduced in amplitude while the response to the left wrist stimulus remained unchanged. Similar results were obtained when the subjoct attended to the stimulus to the left wrist; i.e., the responsu to the stimulus to which the subject was attending (lon wrist stimulus) was reduced while the response to which the subject was not attending (right wrist stimulus) was unchanged. These findings were statistically significant at the 0.05 to 0.01 level in five subjects.

(Supported by USPHS Grants MH-04808 and M-5806, NIMH).

\section{Auttery evoked respomens durius difierent stages of} sleep in man. - E. D. Weltaman and H. Kremen (New York, N. Y.).

Evoked responses to an auditory click $(50-60 \mathrm{db})$, obtained during the various stages of natural sleep from scalp electrodes in ten normal subjects, were averaged by means of a Mnemotron CAT special purpose computer. In this study responses were obtained from a bipolar vertex-occipital electrode placement. Approximately 25 evoked responses were obtained per subject per night, each response being an average of either 100 or 240 clisks, presented at varying intervals from 1/sec to 1 every $4 \mathrm{sec}$. Sleep stages were defined, from an all night continuously recorded EEG, according to Dement's classification. In five subjects simultaneous posterior neck muscle responses were averaged. When simultaneous posterior neck muscle and scalp recordings were made, an averaged evoked response was never obtained from the neck musele electrodes during any of the sleep stages.

The averaged evoked response obtained from the scalp electrodes consisted of a series of negative and positive waves with the following peak latency ranges: $N_{1}=40-70$ msec, $P_{1}=80-130$ msec, $N_{2}=140-230$ msec, $P_{y}=250-400 \mathrm{msec}$ and $\mathrm{N}_{3}=650-950 \mathrm{msec}$. The sign of the wave is as obtained at the occipital electrode with reference to the vertex. The latencies of the early waves $\left(\mathbf{N}_{1}, \mathbf{P}_{1}, \mathbf{N}_{8}\right)$ generally remained constant during all stages of sleep, whereas the latencies of the later components ( $\mathrm{P}_{2}$ and $\mathrm{N}_{\mathrm{g}}$ ) significantly increased. The major alteration in the evoked response as the EEC changed from waking through stages 1 to 4 sleep was a clear and consistent augmentation of the later components, $P_{2}$ and Ns. During the rapid-eye-movement stage of sleep the amplitude of the evoked response was smali and approximated that obtained during the waking state.

These findings suggest that the auditory evoked responses obtained during sleep represent averaged "K complexes", and that they are present in all stages of sleep.

\section{Evoked potentials in hemiplegic patients. - W. T. Liberson and D. Scott (Hines, mi.).}

Evoked responses to a stimulus applied to the median nerve were studied with the use of the CAT. The contralateral central and occipital electrodes were used with the ear as a reference electrode. The most constant component of the evoked response was represented by a 50 to 60 msec peak latency negative wave recorded on the contralateral central region (the "intermediate component" or IC wave). In hemiplegic patients, a suppression of this response is always followed by a suppression on the same side of the late components related to the V-potential of Pauline Davis.

Two groups of hemiplegics suffering from a recent CVA (within 4 months) were differentiated on the basis of preservation or suppression of IC waves. All but one had a clinical diagnosis of mid-cerebral artery thrombosis. The remaining patient had internal carotid artery thrombosis.

Group 1 (5 patients), having similar IC waves on the involved and normai hemispheres, contained only one aphasic (pure motor aphasia); EEG records were normal in three patients. Group 2 (6 patients), with IC waves suppressed on the involved hemisphere, contained three aphasics; four had high amplitude delta foci and only one had a normal EEG record.

Therefore, patients in whom IC waves were the same on the normal and involved sides seemed to show a lower incidence of cortical involvement.

\section{Recovery functions of peripherul nerve and somato- sensory cortex in man. - C. Shegnos and M. Schwartz (lowa City, Iowa).}

Previous studies of human somatosensory cortical recovery function, using paired "conditioning" and "test" stimuli, showed that degree of recovery of the primary component was related to psychiatric status. The influence of peripheral factors on relevant individual differences was left in question. This study was carried out to determine the extent to which the recovery function of peripheral nerve influences that of cortex. An additional purpose was to obtain a detailed description of early recovery in both nerve and cortex.

Eleven subjects were studied. The inedian nerve at the wrist was stimulated percutaneously. To restrict the nerve response to sensory fibers, intensity was adjusted to a level just below that required to produce an EMG response from the thenar eminence. Nerve potentials from leads at the elbow and cortical responses froni bipolar scalp leads were recorded simultaneously with two Mnemotron averagers. Intervals between "conditioning" and "test" stimuli were increased in $1 \mathrm{msec}$ steps from 1 to $20 \mathrm{msec}$, in 5 msec steps from 20 to $30 \mathrm{msec}$, then in 10 msec steps to $100 \mathrm{msec}$. An automatic subtracting device permitted the response to the "test" stimulus to be recorded on a separate channel from that to the "conditioning" stimulus.

Previous findings of carly amplitude recovery at cortex, usually before $10 \mathrm{msec}$, were confirmed. This was true for several later components as well as for the primaiy. Latency recovery was not synchronous with amplitude recovery. Nerve recovery was usually complete by $5 \mathrm{msec}$, and was followed by a period of "supernormality", lasting $10 \mathrm{msec}$, and a long-lasting phase of "subnormality". Nerve and cortical recovery were not significantly related; they appear to be independent functions.

(Supported by USPHS Grant MY-2635, NiMH, and lowa Mental Health Research Fund). (Full paper in Electroenceph. clin. Neurophysiol., 1964, 17: 126-135). 
25. Characteristies of visually evoked responses in normal sablacts and schinophrealc patients. - E. Rodin, G. Zecharopoulos, P. Beckett and C. Frohman (Detrolt, Mich.).

The characteristics of visually evoked responses were studied by means of a Mnemotron Tape Recording System and a Mnemotron Computer of Average Transients in two groups of ten normal subjects and two groups of ien schizophrenic patients. In view of considerable individual differences, only the group results will be presented. The two groups of normal subjects showed very similar response characteristics. With eyes closed and bipolar linkages (occipital to posterior parietal), the following latencies were obtained: a positive peak at 50 msec, a negative peak at 70 msec, a positive peak at $140 \mathrm{msec}$, and a negative peak at $190 \mathrm{msec}$. The second group of normal subjects showed, in addition, a negative peak at 35 msec. When the subjects had their eyes open, the initial positive peak appeared slightly earlier (40-45 msec); the negative 70 msec peak remained unchanged, but the positive 140 msec peak appeared at 120 msec. The overall amplitude of the potential was reduced.

When stimulation was carried out at $3 \mathrm{f} / \mathrm{sec}$ instead of If fisec, the potential increased somewhat in complexity and decreased in amplitude. Mental activity (calculations) while the patient was being flashed at a rate of $3 \mathrm{f} / \mathrm{sec}$ did not lead to appreaiable changes in the potential when compared with the resting state.

The first group of ten schizophrenic patients showed a response moru complex and of markedly smaller amplitude than the normal groups. The second group of schizo. phrenic patients showed no difference in the latencies of the components when compared with the normal groups. but the overall amplitude of the response was decreased. The differences between these two groups on biochemical measurements of energy metabolism and the relationships of the evoked potentials to charueteristles of the resting EO tracing will be discussed.

26. The spllieg wave pattem and its production by atimulation of the retleular formation. - B. Weir (Montrenl, Canada). Award whming poper, Womer's Auxillary Prize.

The term "spikeand-wave" stems from the original description of a smooth, sinusoidal negative potential. It is evident now that this is an oversimplification. A single complex has its onset not with the negative "spike" but with a much smaller, shorter lasting negative potential (spike 1) which is preceded and followed by conspicuous positive transients which fuse with the downgoing limb of the wave, creating the illusion of a true dome. At the end of this positivity the classical spike (spike 2) begins. Spike $I$ is highest over temporal cortex and smallest or absent frontally. It may be present ilı only one of two homologous areas.

Electrical stimulation of the brain-stem was under. taken in cats in an attempt to reproduce the pattern of human spikes-wave which characterizes petit mal. High

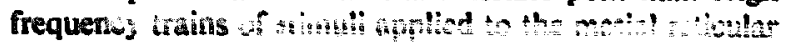
formation can evoke the potential. The region yielding it extends from the medulla to intralaminar thalamus and has its lowest threshold in the mesencephalic reticular formation. The response can be recorded from widespread cortical areas and is maximal frontally and mesially. The strongest projections are to gyrus proreu: and anterior gyrus lateralis. The potential has a short-latency, small amplitude negative spike followed by a positive transient. $A$ variable spike of longer duration and usually larger amplitude then appears, which is followed by the wave. Paralyzing the animal does not affect the response. $A$ negative shift in the steady potential accompanies the spikes-wave. The response to train stimulation of the reticular core has a frequency preference in the vicinity of $3 / \mathrm{sec}$. Concurrent photic stimulation increases the amplitude of the response over visual cortex. The pathway for the response as indicated by lesion experiments is structurally diffuse. The motor concomitants of trains of stimuli are bilateral eye and facial twitching, with myoclonic jerks of the extremities occurring at higher voltages. The cat brain is capable of producing 3/sec spikes-wave discharges following hemorrhagic lesions in the pontine reticular formation. Metrazol-induced spikes-wave haveall the features noted above. Unit studies (done with Drs. D. Pcllen and P. G. Sie) showed variable changes in the response of cortical units to mesencephalic stimulation. When influenced, they usually fired with the spike 1 or 2 phase and not during the wave. The electrical stimulation of the reticular core in the chronically implanted cat can produce a spikes-wave like response at the same time as the animal shows motor changes similar to those occurring in some types of petit mal.

This work supports the concept of the unity of the centrencephalon and the reticular system. It is likely that petit mal involves this region as well as the cortex. The term spikes-wave is more accurate than spike-and. wavo in describing the EEG pattern which characterizes the petit mal seizure.

27. Ro-ovaluation of focal and "diatant" discharges and clinical algns in the light of 135 brain tumor necropiles. - B. K. Bagchi, A. Cuvener and K. A. Kool (Ana Arbor, Mich.).

Out of over 1000 brain tumor EEG records, most of them studied with our previously published elaborate EEG technique, 135 cases with autopsy have been chosen for this report. Without post-mortem examination, even in operated cases, there may be inadequate information about tumor location. Good agreement existed in only $45 \%$ of operated and autopsied cases. Partial agreement was found in $43 \%$. In the remainder, tumor was not in evidence or localization was false at the time of surgery. In the group with partial agreement, hemispheric and/or deep extension could not be specified in the surgical notes. Thus, reports in the literature about correlation between EEG localization and tumor site with surgery and/or contrast study, but without autopsy, may be misleading.

Information on 100 electroclinical variables was gathered. Comparison was made between tumor location and wave form and wave topology. Sn-called "distant" dis- 
charges were re-evaluated. An attempt was made to correlate tumor histology with EEG signs. Particular attention was paid to the types of deita waves (high monomorpluic, irregular polymorphic, lower and slower deltas, etc.), their incidence, antero-posterior, latero-medial distribution, synchronous bilaterality, shift and overall unilateral emphasis.

Attention to precise distribution patterns is important for adequate analysis of possible mechanisms of "distant" discharges. Deep one-sided posterior quadrant cerebral tumors without increased intracranial pressure, but with local slow delta signs, may produce synchronous or asynchronous "distant" uni- or bifrontal deltas of a slightly different type (? through occipito-frontal fasciculus discharge pathway). The present study also validates and enlarges upon the concept that, within the framework of certain clinical reservations, deep level nonpunctate EEG signs are usually discriminative of noninvolvement of an upper convexity area.

\section{Vertigo and EEG. - E. Niedermeyer and R. Hinchclifie (Lown City, Iowa).}

The EEG was recorded in 70 unselected patients who were complaining of vertigo. Each patient also received a comprehensive neuro-otological examination, which included otoscopy, audiometry, vestibular tests and a neurologic examination. Psychological studies were also performed. Thirty-one patients were in the age range 11 to 40 years, 29 in the range 41 to 60 years, and ten patients were older than 60 years.

The EEG was abnormal in nineteen cases and normal in S1. Classical seizure potentials, such as negative spikes, spike-wave complexes and marked sharp activity, were wot recorded. Generalized slow activity (7 cases) and slow nctivity over the temporal area (8 cases) were the most conmon abnormalities. Unilateral temporal abnormalities were seen only over the left side. In three patients there was minor sharp activity over the left temporal region. In addition, three individuals showed 14 and 6/sec positive spikes. Two of these patients were aged 14 years, and the third was aged 29 yeurs.

Tho most frequently encountered clinical diagnosis was "Meniere's disease". In several of these cases, there was some evidence of cerebrovascular insufficiency. An atternpt was made to distinguish between vertebrobasilar artery insufficiency and other vertiginous conditions on both clinical and EEG grounds. Other diagnoses included traumatic vertigo, toxi-infectious vertigo, stato-acoustic neuritis, brain tumor and demyelinating disease. EEG studies seemed to be helpful in the differential diagnosis of vertiginous conditions, differentiating between lesions confined to the peripheral vestibular system and those involving the central vestibular system (with or without labyrinthine involvement). Emphasis is also laid on the lack of demonstrable epileptic mechanisms in our cases.

29. Electroencephalographic prognosis in acute cerebral anoxin (cardilac or respiratory arrest). - J. M. Hockaday, E. Epstein, F. Potts, A. Bonazxi and R. S. Schwab (Boston, Mass.).

In 1962, we reported that the occurrence of a persistent totally flat EEG in a patient without spontaneous respiration or reflexes indicated cerebral death. Maintenance of restored cardiac function and mechanical respiration should not be continued. This report deals with 34 patients with histories of cardiac or respiratory arrest who had some survival of medullary or mid-brain function, and the analysis of the prognosis from the EEG findings.

From 13,520 IBM processed EEG reports over the past 4 years, we recovered 550 reports of coma recordings. There were $30 \%$ of these whose coma had cleared at the time of the EEG recording. A review of each hospital record revealed 34 patients who suffered cardiac arrest (22), or total respiratory ariest (12). The clinical and EEG outcome of these 34 cases showed the following: (1) recovery to a normal EEG and normal neurological state (3 patients), (2) recovery of consciousness with a persistent abnormal EEG and obvious gross intellectual and cerebral damage ( 3 patients), ( 3 ) early death, within 2 weeks, with no significant recovery of brain function (23 patients), and (4) late death with only slight brain function present ( 5 patients).

Total anoxia of over $10 \mathrm{~min}$ duration is a wretched and hopeless catastrophe, and serial EEGs with flat or nearly fiat tracings were seen in the fatal cases. $A$ brief (under $5 \mathrm{~min}$ ) anoxia was related to EEG records of abnormal waves without voltage depression and return to normal in a few days. Such fortunate patients recover fully in both EEG and clinical state. Flat records that slowly improve over weeks are associated with persistent and serious brain deficits. The worst prognosis is well correlated with slow EEG improvement and persistence of severe voltage depression, and all such patients have died. Serial EEGs are necessary for establishing prognostic value, which, of course, must be fully integrated with the clinical state of each patient.

\section{Fractionated intracarotid Metrazol Injection: new dlagnostic method in electroencephaloxraphy. - P. Gloor, T. Rasmussen and F. Maroun (Montreal, Que., Canada).}

Many complex problems encountered if the electroencephalographic examinations of patients presenting seizure problems, especially when a decision has to bo reached whether neurosurgical treatment is indicated or not, require the application of special techniques that go beyond the limit of the routine EEG examination. At the Montreal Neurological Institute, the injection of Sodium Amytal into the carotid artery has in the past proved helpful in analyzing some of theso problems, especially those representing bilateral and synchronous epileptiform discharges. In the course of these investigations, it was felt desirable to complement this examination by the use of fractionated injections of Metrazol through the carotid route. It was hoped that in this way the lateralization of the lowest threshold area and the comparison of Metrazol thresholds of one hemisphere versus the other would help to further elucidate the origin of the patient's seizures.

Twelve patients have been subjected to this intracarotid Metrazol test up to the present date. The findings obtained were in general complementary and confirmatory 
of those obtained from intracarotid Sodium Amytal injections. A very marked difference in the Metrazol threshold of the two hemispheres is found in cases with a unilateral cortical focus, even if it gives rise to secondary diffuse and bilateral discharges, whereas in epilepsies of centrencephalic origin no such difference in threshold, or only minor ones, could be demonstrated. There remain, however, intermediate cases which present problems that are not easily resolved by either one of the two techniques. (Full paper in Electroenceph. clin. Neurophysiol., 1964, 17: 322-327).

31. Single neurom and laminar recording of the human epileptiform spike. - M. Rayport and H. J. Waller (New York, N. Y.).

The epileptiform spike occupies a central role in the diagnosis, localization and treatment of focal cortical epilepsy. Electrophysiological investigations utilizing laboratory models (pharmacologic, chemical, physical) of the cortical EEG spike have disclosed the development of "mirror" spike foci and have shown the electromorphological similarity of "primary" and "secondary" cortical spikes. The present investigation was undertaken to achieve a detailed intracortical analysis of the archetype, the spike of human epileptogenic cortex. Specifically, the aim was to delineate the patterns of cortical unit activity in focal epileptogenic cortex, and to analyze the relation of cortical unit discharge and intracortical slow wave activity in the intracorticogram (ICG) recorded from the micro-electrode to the corresponding epileptiform spike at the overlying pial surface.

Single neuron activity and slow potentials have been simultaneously recorded with micro-pipettes $(1-3 \mu$ tip diameter, $2.5 M \mathrm{KCl}$ ) from the cortex of pationts under. going craniotomy under local or general anesthesta for treatment of drugeresistant focal selzures. Penetrations were made normal to the exposed pial surface in cortex showing maximal epileptiform spike aetivity by electro. corticography. The spontaneously occurring cpileptiform surface potentials were monitored $1.5 \mathrm{~mm}$ from the site of penetration.

Extracellular discharges of more than 65 single neurons have been recorded at depths of 50 to $7544 \mu$ in over 24 penetrations in nineteen craniotomies. Comparison of the intracortically recorded epileptiform potentials with the surface "spikes" revealed two distinctive types of intracortical potential distribution. In the first type ("A"), a prominent initial deep positivity was followed by a slow negative wave. Single neurons recorded during such a penetration fired during, but not in correlation with any one component of, the slow potential. The second type ("B") was characterized during penetration by the appearance of an initial brief deep negative wave replaced at greater depth by initial positivity. Single neurons fired during an apparent phase of strong activation, represented by the rising front and peak of the early deep negative component of the ICG slow potential. Discharges from more than $50 \%$ of recorded units had no obvious correspondence with the occurrence of surface spikes. Bursts of 3-10 unit discharges lasting $10-100$ nisec were recorded, but high frequency discharge of many seconds duration of apparently uninjured units was not encountered.

(Supported by USPHS Grants NB-01725 and NB-02080, NINDB).

\section{Perlodic lateralized eplleptiform discharges in FEG:} electrographic, clinical and pathological correlations, G. E. Chatrian, C. M. Shaw and H. Lefiman (Seattle, Wash.).

Periodic lateralized epileptiform discharges (PLED) were recorded in 33 subjects. These discharges consisted of sharp waves, spikes, multiple spikes or more complex bursts repeating periodically or quasi-periodically at rates often close to $1 / \mathrm{sec}$. The discharges were separated by intervals of apparent quiescence or by slow waves.

Twenty-nine out of 33 patients experienced epileptic seizures which consisted of epilepsia partialis continua in seven cases, of reiterative, sporadic or isolated focal motor seizures in eighteen cases and of continuous psychical seizures in four cases. Four subjects did not present detectable clinical signs of seizure activity. In addition, all patients with PLED exhibited other symptoms and signs of impaired neurological and mental function, especially motor and sensory deficits, visual field defects and alterations of symbolic functions.

The etiology of the lesion or disorder was represented by: cerebral infarct(s), thirteen cases; recent extension of old infarct or chronic focal seizure disorders, seven cases; chronic focal seizure disorders, three cases; spaceoccupying lesions (metastases and glioblastomas), eight cases; pneumococcal meningitis, one case; and postvaccinial encephalomyelitis, one case. There was a high incidence amonis these subjects of chronic alcoholism and severe systemic metabolic disorders including uremia, alterations of fluid and electrolyte balance and of acidbase equilibrium. Autopsies were obtained in six out of twelve patients who expired.

An uttempt is made to correlate the electrographic, clinical and pathological findings in this group of patients. (Full paper in Electroenceph. clin. Neurophysiol., 1964, 17: 177-193).

\section{Central (Rolandic) foci in chlldren: an analysis of $\mathbf{2 0 0}$ cases, - J. M. B. Smith and P. Kellaway (Houston, Tex.).}

Two hundred children with central foci, ages birth through 16, have been studied. The central focus was the only specific electrographic abnormality in all the cases. In all but two cases in which there was a slow wave focus, the focus was either of spike or sharp wave type. In 29 cases the spike foci occurred independently in the right and left central regions, and in the other cases the foci were unilateral.

Seizures were present in $59 \%$ of patients. The types of seizures observed in these patients were generalized tonic or tonic clonic in $50 \%$, focal motor in $29.7 \%$, focal sensory in $7.6 \%$ and generalized seizures with focal features in $22.9 \%$. Other neurological findings included spasticity or poor coordination in $22.5 \%$, mental retardation in $31.5 \%$, 
behavior disturbance in $11.5 \%$ and convulsive equivalent symptoms in $20 \%$ of cases.

Centrai ioci were first demonstrated between the 4th and 6 th year in $40 \%$ of cases, but $38 \%$ of cases had onset of symptoms during the first year of life. Follow-up studies showed a tendency for central foci tisappear, with persistence for more than 4 years being rare.

Identification of the etiological factors responsible for the production of central foci could not be made in $60.5 \%$ of patients, and even in the other $39.5 \%$ the evidence was often only suggestive.

\section{Autonomic response during paroxysmal EEG activity. -} L. C. Johnson and R. A. Davidofi (San Diego, Calif.).

Simultaneous recordings of EEG, heart rate, galvanic skin response (GSR), finger temperature and respiration were obtained during bilaterally synchronous paroxysmal EEG activity from 54 patients with a history of seizure disorder and five non-epileptic "photo-activators". Photic stimulation was used to induce paroxysmal activity in six patients and in the five epileptic subjects. The patients were categorized as to type of burst - slow wave (SWB), atypical spike and wave (ASW), multiple spike (MSB), or petit mal (PMT) - and whether or not there was an observable manifestation of the paroxysmal discharge.

Results obtained from analyzing 191 discharges indicate a continuum of autonomic response during paroxysmal activity: SWB.

1. No autonomic response was associsted with any

2. Autonomic response was not associated with subclinical ASW.

3. The degree of autonomic involvement during clinical ASW discharges depended upon the extent of the clinical response; GSR was generally present; heart rate change was second in frequency of occurrence.

4. A GSR and a change in heart rate were present during nearly all petit mal discharges, but respiration and temperature responses were variable.

5. Total involvement of the autonomic nervous system was present during grand mal seizures.

The latency of the autonomic response, especially GSR, differed significantly for ASW and PMT bursts. Regardless of duration of the burst, the GSR response occurred within the expected latency of 1.5 to $2 \mathrm{sec}$ following the first spike of the ASW bursts, but for PMT, the GSR response occurred several seconds after onset or, more frequently, following the cessation of the discharge. These observations of the GSR and the response latencies of the other autonomic variables suggest that awareness of the manifestations of the discharge may be an important determinant of autonomic response.

(Full paper in Electroenceph. clin. Neurophysiol., 1964, 17: 25-35)

35. Behaviomal responses to stimulation of human hippocampus, hippocampal gyrus and amygdals. - R. D. Walter, L. Chapman, R. Porter, P. Crandall and R. Rand (Los Angeles, Callf.).
During evaluation for temporal lobectomy, ten patients with psychomotor seizures were stim inted via chronically implanted bipolar depth electrod. 'stresholds for evnked responses, paroxysmal after-discharges and watical seizures appeared to be of significant value in supplementing routine sleep, waking and sphenoidal recordings as a means of identifying abnormal sites. A number of subseizure behavioral responses observed were the familiar components of epileptic auras: epigastric sensation, fear. déjd $v u$, sensations of odors, falling, taste, hearing music, staring and brief unresponsiveness. In one patient, stimulation which resulted in bilateral hippocampal afterdischarge, but no clinical seizure, temporarily induced a state in which memory for the events from 2 min to 2 weeks in the past was unavailable. Other aspects of mental functioning appeared intact. Stimulation in one or more sites resulted in re-experiencing a brief epoch of past experience in all but one of these patients. This pher:omenon followed stimulation of the hippocampus in some patients and of the amygdala in others. In one patient, stimulation of the amygdala on the apparently normal side, not accompanied by paroxysmal discharge, evoked the simultaneous recall of several unintegrated memory fragments which lacked the dreamlike quality of reexperiencing a past event. In contrast, stimulation of the amygdala on the abnormal side resulted in a state reported to be highly pleasurable. The threshold for self. stimulation appeared to be identical with the threshold for local paroxysmal discharge.

Stimulation of the contralateral amygdala resulted in a highly utipleasant feeling of apprehension, tension, guilt, depression and a conviction of impending disaster.

36. The neurologic status of children with early infantlle autism: an electroencephalographic survey. - P. T. White, W. DeMyer and M. DeMyer (Indianapolis, Ind.).

Early infantile autism is a severe psychotic disturbance occurring in young childron. The concept of this illness, first conceived by Leo Kanner in 1943, has ultimately become somewhat better established und more accepted. However, there is still uncertainty as to the basic etiology of the condition. A study has been undertaken neurologically and electroencephalographically in an attempt to determine to what extent organic brain disturbances contribute to the picture of early infantile autism. A total of 58 children with early childhood schizophrenia or autism was studied neurologically and with a series of electroencephalograms. The electroencephalograms were taken in a normal waking state when possible. These were supplemented in each instance by records taken during drowsiness and sleep induced with intramuscular Sparine. The results in this group were compared to the results of a similar study in an additional 104 children representing normal controls, children with known organic brain damage, pseudoneurotic schizophrenics, severe nonpsychotic personality disturbances and neurotic children.

The electroencephalograms were all evaluated without knowledge as to the diagnosis of the indiv dual child. Approximately $55 \%$ of the children diagnoseci as early 
infantile autisms showed specific types of EEG abnormalities such as spikes, spike-wave forms, or combinations of focal and disseminated abnormalities. These occurred spontaneously, as well as in relationship to sieep, occurring normally or induced by Sparine. In certain groups of the other disturbed children, there was also a high percentage of fairly specific types of indicators of organic dysfunction. In the control groups these specific indicators were absent or very infrequent. A statistical correlation and comparison of the groups indicates that there are important organic contributions to the variety of emotional disturbances that occur in children and, in particular, in relationship to early infantile autism. Although firm and distinct neurologic signs are infrequent, many of these children also demonstrate minor neurologic deviations which tend to support the elestroencephalographic findings and provide further evidence for organic contributions to these disease entities.

37. A study of the behwilor and EEG patterns of patients recelving tranqullizers with and without the addition of chlordiaxepoxide. - G. A. Ulett, A. F. Heusler, R. Quick, V. I, Word and C. Bowers (St, Louls, Mo.).

A sample of 21 hospitalized, chronic regressed psychotic female patients was divided into three groups of seven patients each. Each group of seven patients was given one of three psychotropic drugs for a period of 11 weeks. During this period on medication, chlordiazepoxide was added to the psychotropic agents in each group during weeks 6 to 9. Electronically analyzed EEG recordings and behavioral observations were made weekly throughout the study.

After a drug free period, the same three groups of patients received the same drugs in an identical manner for an additional 11 week control period. During this second contiol period, placebo was substituted for tho chlordlazepoxido.

The hypothesized effects of Librium's ability to reverse tranquilizer-indueed EEG changes were observed. In addition to this, an improvement in behavlor was noted during the chlordlazepoxide-tranquilizer period.

\section{Paplledean and the electroencephalogram. - D. Stiverman (Philadelphia, Pa.).}

Papilledema, defined as passive noninflammatory edema of the optic dises from any cause, is an important neurologic sign that may indicate intracranial disease. This study was undertaken to determine what value the EEG might provide in the total evaluation of patients with papilledema. It was limited to patients with such an ocular condition (confirmed by the ophthalmologist) who had one or more EEGs and who underwent definitive examinations or who were followed for a sufficient time to establish a diagnosis with cartainty. It was found that the EEG varied from normal to diffuse or focal slow. Papilledema from local eye disease, from systemic disenses such as hypertension, electrolyte imbalance or endocrine hypofunction, and from the entity known as pseudo. tumor cerebri is associated with a normal EEG or minor abnormalities (the rare exceptions will be discussed).
Likewise, no significant electrical abnormalities were seen in cases of chiasmal or posterior fossa arachnoiditis, otitic hydrocephalus, one aneurysm (anterior communicating artery), one sphenoid ridge meningioma and several intraventricular (especially third and fourth ventricle) and posterior fossa tumors. Space-taking, destructive or inflammatory lesions of the cerebrum were almost invariably associated with focally slowed EEGs. The clinical value and the significance of these observations will be discussed.

\section{The electroencephalogram in difiuse encephalopathies. - P. Gloor, O. Kalabay and N. Giard (Montreal, Que., Canada).}

Electroencephalograms in diffuse encephalopathies often show paroxysmal, bilaterally synchronous slow waves or slow spike-and-wave discharges, changes that are often considered to be characteristic of projected disturbances arising from subcortical grey matter. Others show asynchronous slow waves. This study was carried out to determine whether there exist any correlations between the distribution of the diffuse lesions and the EEG pattern. The electroencephalograms of 32 pationts suffering from various forms of diffuse encephalopathies and who had come to autopsy were studied in the light of the pathological findings.

A close correlation was found between the occurrence of bilaterally synchronous paroxysmal discharges of a slow wave or slow spike-and-wave type and the presence of diffuse pathological lesions involving cortical and subcortical grey matter. Diffuse asynchronous and irregular slow waves were characteristic of diffuse involvement of the cerebral white matter. Patients with combined involvement of white and grey matter, the latter at both cortical and subcortical levels, showed a combination of both these EEG patterns. In diffuse cortical grey mutter disease without involvement of white matter or superficial grey matter, there was some tendency to paroxysmal synchronization. However, this was often confined only to one hemisphere, and sustained, diffuse bilateral paroxysmal synchrony was exceptional.

These findings suggest that the most favorable conditions for the genesis of diffuse, bilateral paroxysmal synchronous abnormalities are given by the presence of diffuse pathological lesions inrolving cortical and subcortical grey matter, whereas asynchronous delta activity is most characteristic of pathological processes involving cerebral white matter.

\section{Critical evaluation of rheoencephalogram (REG) in "normal controls" and cerebrovascular disease. - $\mathbf{C}$. Perez-Borfa and J. S. Meyer (Detroit, Mich.).}

With techniques available commercially, REGs were made on nineteen control subjects and 28 with proven cerebrovascular disease. After analysis of these data, it did not appear that the REG is a technique which provides reliable or consistent clinical information of use in the diagnosis of cerebrovascular disease. It seems evident that a significant proportion of the pulse wave is derived from extracranial blood flow. Despite the ease of its 
application and its harmlessness, more basic information is required which may define the complex factors influencing the REG wave recorded from the intact scaln. Only then its clinical usefulness may become apparent. At the present time, the REG record is of no obvious diagnostic value and may actually be misleading in the attempt to diagnose the location of cerebral vascular disease.

\section{Subacute spongiform encephalopathy: comment on the literature and case report. - J. G. Small, V. R. Bleisch and R. M. Woolsey (St. Louis, Mo.).}

Prominent EEG abnormalities are associated with a clinically distinct variety of subacute degeneration of the brain. The characteristic manifestations of this disorder include presenile mental deterioration, hypokinesia, mutism, myoclonic seizures and visual failure. Some authors classify such cases in the Creutzfeldt-Jakob group, whereas Heidenhain, Nevin and others consider this syndrome to be a specific disease entity, separable from other degenerations of the central nervous system. The clinical, EEG and neuropathological findings in the case of subacute spongiform encephalopathy to be presented lend support to the latter view.

The 6 month clinical course of this 54 year old female progressed from an acute mental disorder of a depressive type to apathy and profound dementia. Generalized muscular rigidity, tremors and myoclonic jerking ensued with rapid decline to a state of akinetic mutism and cachexia with myoclonic and generalized convulsions. Serial EEG studies demonstrated an absence of normal rhythms with regularly recurring diffuse, bisynchronous paroxysms of high voltage diphasic and triphasic slow waves and single and multiple spikes. In the terminal stage there was very frequent periontic spiking separated by intervals of isoelectric background potential.

Post-mortem examination revealed atrophy of the cerebral cortex. Microscopically, acute pyknotic degeneration of neurons, most severe in tho occipital cortex, was associated with mark ed astrocytic proliferation, occasional lipid phagocytosis and status spongiosus. Thalamus, basal ganglia and the granular layer of the cerebellum showed similar degeneration.

The EEG and pathological material will be presented. The EEG in this disorder will be compared with electroencephalographic findings in other types of presenile dementia.

\section{The significance of unllateral bursts of activity in the aiphs range. - R. Jafie and A. H. Weiss (New York, N. Y.).}

Unilateral bursts of activity in the alpha range are a rareiy encountered but readily distinguishable pattern. The pattern consists of fairly regular sinusoidal activity, usually of 60 to $90 \mu \mathrm{V}$, in the frequency range of 7-12 c/sec. It appears consistently in unilateral bursts, often of increased voltage, and with a duration of $0.5-4.0 \mathrm{sec}$. This pattern is definitely paroxysmal, and is not to be confused with the consistently slow alpha of enhanced or reduced voltage, which is often seen in temporal leads on the side of a focal brain lesion. The activity is, at times, accentuated during slight drowsiness and hyperventilation.

Twenty-eight cases showing this finding are described, in twelve of whom it is the only electrical abnormality seen at some point in the clinical course. The other patients showed additional, variably severe EEG abnormalities. Seventy-five per cent of the patients showed clinical or radiographic evidence of bilateral or midline lesions, or diffuse cerebral dysfunction. In most of these instances, the EEG abnormality was seen on the left side. The remaining $25 \%$ of the patients had focal pathology. In these cases, the burst abnormality was recorded on the side of the lesion.

It is concluded that this electrical abnormality is a reliable indication of the presence of organic brain disease or dysfunction, but is not of specific significance in terms of localization or etiology.

\section{Intravenous penicillin-Induced convulsions: a case report. - W. L. Smith and R. S. Dow (Portland, Ore.).}

A 66 year old male with subacute bacterial endocarditis developed progressively severe focal seizures and then grand mal convulsions while receiving large doses of intravenous penicillin. The seizures progressed in spite of a vigorous anticonvulsant regimen. However, when the penicillin was discontinued, all seizure activity ceased within $6 \mathrm{~h}$.

Serial electroencephalograms correlated well with the patient's clinical course and later, when the penicillin was restarted at a lower dosage schedule, the electroencephalogram became more abnormal, although no clinical seizures were observed. Serial blood and cerebral spinal fluid penicillin levels were also determined.

The authors reviewed the patients with subacule bacterial endocarditis or with meningitis who received penicillin therapy at the Good Samaritan Hospital, Portland, Oregon, during the period of 1942 to 1962 . The literature regarding direct application of penicillin to the cerebral cortex in man and animals is discussed, and the experimen. tal data regarding blood and cerebral spinal fluid penicillin levels are revicwed. The possible implications of our clinical observations regarding the pathogenesis of some convulsive seizures as related to the blood-brain barrier are discussed.

\section{14 and 6/sec positive splices in twins and triplets. - R. J. Ellingson, H. Rassekh and A. 1. Finlayson (Dmaha, Neb. and Councll Blufifs, Iowa).}

Almost identical patterns of 14 and 6/sec positive spikes have been observed in two sets of twins and one set of triplets within the last 2 years. The first instance was in monozygotic 18 year old male twins, one of whom was referred because of episodes of dizziness following an athletic accident. The other twin was asymptomatic but showed the same EEG pattern. The second instance was in very unlike fraternal twins, age 6 , who had been studied from birth in connection with a longitudinal study of EEG development. The male twin is small and displays chondrodysplasia of the long bones. The female twin is of normal stature and is asymptomatic. The third instance 
was in monozygotic triplets, age 16, one of whom was referred because of headaches, blackouts and abdominal pains. The other two displayed no such symptoms, but all three are mildly retarded. EEGs of the mother, who is epileptic, and other members of the family have also been recorded. The significance of these data for the question of etiology of 14 and $6 / \mathrm{sec}$ positive spikes will be discussed.

\section{Electroencephalography in neosatal seizure states. -} C. T. Lombroso and A. Rose (Boston, Mass.).

The nurpose of this study was to inquire into the prognostic value of the iectroencephalogram in neonatal convulsions. Newborn infants who develop seizures tend to fall into (wo groups: (I) a majority whose convulsions cease after days or weeks and whose development proceeds normally, and (2) a minority who either die early or survive with severe neurological deficits. Examinations and tests are often unhelpful in predicting early to which group a given infant will belong.

We were able to demonstrate that the morphological features of early electroencephalograms correlated well with the clinical outcome. We studied 75 infants with convulsions in the neonatal period and followed them for $2-3$ years on the average. Serial electroencephalograms were obtained and classified as: (1) normal, (2) unifocal (with normal background patterns), (3) multifocal, (4) hypsarhythmic, and (5) flat. Borderline tracings were classified as normal. Thirty-three of the initial electroencephalograms were normal. Hypocalcemia and hypoglycemia were present in $30 \%$ of the cases in this group. Twenty. eight of these patients did quite well. The most frequent abnormality in the electroencephalogram was localized diphasic blunt spikes. In twelve out of 24 cases they wers situated in the right rolundic area. In nine there was definito hypocalcemis. In the great majority, these patients also did quite well. The multifocal group, although only leven cases, appeared to show in contrast sovoro prognostic clues; all in this group either died early or had gruss defieits on follow up. Two developed classic hyps. arhythmic dectroencephalograms. A relatively large grosup of neonatal electroencephalograms could be classified as hypsarhythmic. It is important to realize that such hypsarhythmic features may appear only in sleep and are not necessarily correlated clinically with infantile spasms. Most of these carly cases of hypsarhythmia in sleep progressed to a fully developed picture of hypsarhythmia in waking. In some, however, it was a transient phenomenon, still constituting a grave prognostic sign. Similarly, poor prognosis is offered by a "flat" electroencephalogram of which we had four.

In summary, relating the clinical outcome to the initial and early electroencephalogram, it appears that in the $70 \%$ of the patients who were doing well, the initial electroencephalogram was either normal or unifocal with normal background. In contrast, in the $30 \%$ of the infants who died or survived with severe deficits, the initial electroencephalogram was either multifocal, hypsarhythnic or flat. We realize that longer follow-up will be necessary to recognize minor neurological defects and to rule out the possibility of recurrent convulsions later.
46. Variation in the form and Incation of transient sharp waves in a focal type of genetic epllepsy. - P. F. Bray (Salt Lake City, Utah).

A longitudinal study has been carrie 1 out in ten families in whom the index case presented with a focal type cf epilepsy. The EEG abnormality in all index cases was characterized by frequent, transient sharp wave discharges which appeared unilaterally or independently bilaterally. The sharp waves appeared with maximal amplitude in the temporal-central-midline area. It seems likely that these cases are the same as those with the common midtemporal spike foci associated with focal clinical seizures described by Gibbs. Fifty-two siblings and nineteen parents of the ten index cases have been studied repeatedly. Nine of the 52 siblings and three of the nineteen parents showed very similar focal sharp wave abnormalities.

The familial occurrence of similar EEG abnormalities in these close relatives, as well as the lack of other positive diagnostic data, strongly suggests a genetic etiology. This report is designed to show the variation in both the pattern and location of the transient sharp wave discharges (1) between affected members of different families, (2) between affected members of the same family and (3) between recordings obtained at different times on the same affected individual.

These observations appear significant because (1) the variability in the electrical recordings from the scalp reemphasizes the need for caution in the interpretation of the origin of focal sharp wave discharges in an isolated recording, and (2) the variability in the location, including the sidedness and the area of maximal amplitude, raises a question about the origin of the discharges. Duspite the usual interpretation that discharges of this type are cortical in origin, the composite findings here suggest that the discharges may have a subcortical or midline origin.

\section{Studles on the $K$ complex and eplleptiform activity from the mesial cortex of unanesthetlod, conuclous monkeyt. J. R. Hughes and J. A. Masurowalkl (Bufralo. N.Y.).}

This paper features the $\mathbf{K}$ complex and also epileptiform activity elicited by intensive electrical stimulation of the mesial surface of twelve unanesthetized monkeys with chronically implanted electrode arrays. The $\mathbf{K}$ complex has been mapped and three prominent loci have appeatud on the anterior, mid-and posterior cingular gyrus. Mapping of the $K$ complex on the lateral surface, where the amplitude was generally lower, also showed three loci on the frontal, central and occipital areas. The lowest frequency of repetitive ictal activity on the mesial surface was seen on the occipital area where frequencies of $3-8 / \mathrm{sec}$ were noted. The highest frequency was seen on the postcentral mesial region where $13-24 / \mathrm{sec}$ activity was noted. The frequency of the discharge did not appear to be related to the threshold of epileptiform activity, but varied only with th: position or locus of the discharge on the mesial surface. The lowest threshold of electrographic seizure activity was on the occipital area, and the next lowest was found on the postcentral mesial region. The effect of repeated electrographic seizures was to produce an increasing amount of 
desynchronization in the epileptiform activity. Large amplitude spontaneous discharges were similar in amplitude within a distance of 7-9 $\mathrm{mm}$ from the focus. This region was considered to contain the cells directly participating in the discharge. Ictal activity, at times, spread slowly across the mesial surface at the average rate of 20-25 $\mathrm{mm} / \mathrm{min}$. This rate of spread may be similar to the rates of spread in the march of Jacksonian epilepsy. Seizure discharges elicited on the superior frontal region may be transmitted to the superior parieto-occipital region. Discharges elicited on the cingular gyrus may be transmitted to the inferior parieto-occipital area. Clinical seizures did not accompany electrographic seizure activity from the mesial poles. Ictal head and eye movements appeared with discharges on the midsuperior frontal girus and on the parieto-occipital region. Generalized seizures were elicited from intensive stimulation of the pre- and postcentral mesial regions. Licking and chewing movements, in addition to ipsilateral tonic-clonic movements, were occasionally associated with seizure activity on the cingular gyrus.

(Full paper in Electroenceph. clin. Neurophysiol., 1964, 16: $561-574)$.

48. Electrographic and anatomical studles of methlonine sulfoximine-induced behavioral and convulgive changes in the cat. - M. L. Proler (Houston, Tex.).

Methionine sulfoximine, the toxic principle of the agenized protein diet, produces in the cat a complex syndrome consisting of: (1) sniffing movements accompanied by profuse salivation and impaired consciousness, (2) episoutic head-turning, sniffing and crouching strongly suggesting apprehension and fear, (3) running fits, at the onset of which the animal may appear fearful, and (4) generalized tonic clonic convulsions.

Bilateral temporal lobe removal, including the hippocampi, did not observably change the character of sulfoximine-induced behuvioral attacks and seizures. Bilateral removal of corebral cortex, basal ganglia and hippocampi significantly altered the syndrome in that the behavioral episodes were more automatic in quality, and the generalized seizures consisted solely of the tonic phase, with absence of the clonic phase.

Electrographic studies of sulfoximine-intoxicated animals revealed the following phenomena:

1. Twitching movements of the face were accompanied by bilaterally synchronous hippocampal spikes, with radiation to frontal and temporal regions. Paroxysms of staring and sniffing were accompanied by $10-12 \mathrm{c} / \mathrm{sec}$ rhythmic hippocampal discharges, with no apparent change in cortical electrical activity.

2. Crouching and head-turning episodes were accompanied by desynchronization of the electrogram, with low voltage fast activity noted in all regions.

3. Cerebral activity during running fits was largely obscured by movement artifact, but sufficient evidence was obtained to demonstrate the absence of paroxysmal neuronal cischarge during all phases of the episode.

4. Electrographic concomitants of generalized seizures were not different from those observed in other types of experimental epilepsy.
49. Relation between resting EEG (baseline activity) and Pentothal-activated EEG. - T. Itil (St. Louis, Mo. and Erlangen-Nuremberg, Germany).

Some investigators suggest that Pentothal-induced changes in the EEG are related to baseline activity (resting EEG), while others disagree. To resolve this question we approached the problem in two ways: (1) Pentothal-induced changes in various resting EEG patterns of normals and patients with organic brain disease were studied, and (2) in resting EEG records, artificially altered by oral administration of tranquilizers, i.v. Pentothai-induced changes were studied. A dosage of $4 \mathrm{mg} / \mathrm{kg}$ and injection rate of $0.5 \mathrm{mg}$ / $\mathrm{kg} / 15 \mathrm{sec}$ were used.

Both investigations have shown that:

1. Intravenous Pentothal changed the resting EEG in a typical manner, dependent on dosage, injection tate and body weight.

2. Pentothal-induced changes in EEG are dependent on the kind, frequency, amplitude, synchronization and rhythmicity of the activity in the resting EEG as these may be modified hy tranquilizers. This relation is observed at threshold (low) dosages, while at high doses this relationship is obscured.

50. Reciprocal innervation in Parkinsonism: an electromyographic study. - J. B. Green (Philadelphia, Pa.).

Bipolar surface electrodes were used to record biceps and triceps activity during active and passive movement in both normal and Parkinsonian patients.

A frequent finding in the Parkinsonian group was simultaneous activation of agonist and antagonist. Biceps and triceps were contracted as one muscle. There was no significant latency between contractions of the "stretched" and "shortened" muscles. A similar synchronous pattern was found in normal subjects at the extreme ranges of the elbow joint.

These findings suggested that receptors in and about the joint triggered a central innervation of the biceps and triceps. Accordingly, the elbow joint was injected with procaine in a number of Parkinsonian patients. A definite decrease in rigidity was noted.

It is concluded that explanations of rigidity based upon the activation of muscle spindles do nor explain identical changes in stretched and shortened muscles. Evidence is presented to indicate the role of joint receptors in the maintenance of rigidity in Parkinsonism.

\section{Emotional behavior as related to minor tremor, $-\mathbf{K}$. Inanaga (Kurume, Japan).}

Ail invisible fine vibration is recordable from the surface of the human body. This phenomenon was called microvibration by Rohracher and minor tremor by the author. The genfeis of minor tremor is not yet clear, but it is considerea to be a synthesized product of muscle tone and vibrations due to the heart beat.

As the vibration shows complex wave forms, frequency analysis was performed by a wave analyser. The frequency distribution of minor tremor, recorded from the thenar eminence of the subject lying on a bed, was found to have a close correlation to the psychophysiological 
state of the subject. For example, the amount of $8-13 \mathrm{c} / \mathrm{sec}$ waves was high in a quiet state, while with mental tension or excitement the amount of 8-13 c/sec waves decreased and the $13-20 \mathrm{c} / \mathrm{sec}$ and $4-8 \mathrm{c} / \mathrm{sec}$ amount increased. The frequency distribution of minor tremor in various psychiatric conditions will be demonstrated, showing that it may be a good indicator of emotional state.

Next, observations on the photically driven minor tremor will be reported. It was recorded by a pickup placed on the eyelid. Frequency analysis of the minor tremor driven by intermittent stimulation at seven frequencies $(6.5,7.5 \ldots 12.5 \mathrm{f} / \mathrm{sec})$ for $10 \mathrm{sec}$ each was performed by an analyser with frequency bands of $1 \mathrm{c} / \mathrm{sec}$ between 6 and $13 \mathrm{c} / \mathrm{sec}$. The relationship between the minor tremor response and emotional states was also istablished.

\section{Dlectroencephalographlc abnormallty in nephrotic syn- drome. - C. T. Lombroso, P. Lerman and M. Elian (Boston, Mass).}

Convulsive disorders may be a complication during the course of a nephrotic syndrome. Serial EEGs were obtained in nephrotic children, ages 2-16 years, prior to the onset of ACTH therapy, following onset of diuresis, and in complete remission. Diminution or absence of normal resting rhythms and the appearance of usually monophasic delta rhythms, often with paroxysmal features, occurred during active disease. At times these changes were exaggerated at the onset of ACTH. There was often a dramatic reversal to normal patterns at the inactive stage.

Correlations with the clinical and chemical status of these patients will be discussed, also in relation to brain fluid compartments.

\section{Cerebral dyerthythmin Induced by reading: subelinleal reallate epllopey. - L. Oottinger, Jr., I. C. GII and H. Nohouialil (Los Angeles, Callf).}

Reading epllepsy and other visunl forms of epilepsy have been of recent interest. This study deals with corebral dysthythmin induced by reading in children with severe reading disorders. A control group of normal readers is included. Fifty children with reading disorders will constitute the study group, while there will be ten patients in the control group. All patients will havestand. ard electroencephalograms consisting of unactivated recording, hyperventilation and photic stimulation. Each child will then be allowed to look at pictures without reading for a control period of 3 to 5 min, and he will then read appropriate material for his age and reading placement for approximately $1 \mathrm{~h}$.

In 28 cases already studied abnormalities have been induced in eight patients, one of whom had an autonomic seizure. Correlative material will include intelligence, reading level, dominance, age and sex. This is not an epidemological survey, but one dealing only with children statistically retarded in reading.

\section{Sywdrome of status pett mal in the adult. - R. E. Shev (San Franciaco, Calif).}

The rarity of status petit mal in the adult is emphasized by the occurrence of only two such cases in 1,700 personally observed epileptic patient:. To further emphasize the rarity of the cocurrence of status petit mal, a review of the literature from 1936 to date revealed a total of only seven such cases. In addition, a review of 12,000 EEGs in four different laboratories revealed only one other such case.

The syndrome apparently has four basic components: a history of childhood grand mal or petit mal seizures; a relatively long period of intellectual dullness and odd behavior, resembling schizophrenia, preceding the onset of the attacks; intellectual deterioration suggesting some insidious degenerative disease process; and intermittent periods in which the patient is entirely free of any of the above listed symptomatology.

The diagnosis of the syndrome is dependent upon (1) suspecting status petit mal might exist, rather than an emotional disturbance, and (2) obtaining an electroencephalogram during the active period when all the symptoms are present. Status petit mal will reveal typical spike-and-wave activity of $3 \mathrm{c} / \mathrm{sec}$.

Two case histories will be discussed in detail, illustrating all points of the syndrome, and the current literature will be reviewed.

\section{Some personallty correlates of unilateral and bilateral temporal lobe EEG abnormalities in peychomotor eplleptics before and after unllateral temporal lobec- tomy. - M. J. Meler and L. A. Freach (Minneapolls, Minn.).}

Do psychomotor epileptics with bitemporal lobe EEG abnormalities exhibit greater indications of personality disturbance on the Minnesota Multiphasic Personality Inventory (MMPI) than do those with unilateral temporal lobe abnormalities? Fifty-three psychomotor seizure patients with unilateral or bilateral temporal lobe epilep. togenie foel and abnormalities, established by at least two EEOs preoperativoly and confirmed olectrocorticographteally at operation for temporal lobectomy, served as subjects. MMPI elinical soale scores and an Index of Psychopathology (Ip) based on the MMPI were obtained both pre- and postoperatively. EEC classifications yielded three independent variables: (1) predominantly left temporal abnormality - predominantly right abnormality, (2) bilateral abnormality - unilateral abnormality, and (3) independent spike foci - bitemporal abnormalities with only a single spike focus.

Statistical analyses of MMPI measures by EEG classification were done utilizing the etest for uncorrelated means. Preoperatively, the bilaterals exhibited more pathological scores on Ip and the Depression, Paranoia, Sohizophrenia and Caudality scale scores. Among the bitemporals, the independent bitemporal spike foci group particularly showed more psychopathological elevaticns. Retested on the MMPI 6 months to 1 year postoperatively, the bilateral group means were reduced in the less patho. logical direction when considered in comparison to the unilateral and nonoperated control groups.

Thus, schizoadaptive behavior characteristics, as measured by the MMPI, were more prevalent preoperatively and more susceptible to improvement postoperatively among psychomotor epileptics with bilateral than with unilateral EEG abnormalities. 
56. An inquiry into MMIPI correlates of the 14 and $6 / \mathrm{sec}$ pooltive spilke phenomena. - R. S. Engelhart and J. R. Knott (Iown City, Iown).

Utilizing 111 psychiatric patients on whom complete EEG data and Minnesota Multiphasic Personality Inventory data were available, an attempt was made to discover whether any differences in MMPI patterns existed between cases with $(N=38)$ and cases without (normal EEG, $N=46$; other EEG abnormalities, $N=27$ ) 14 and $6 / \mathrm{sec}$ positive spike activity. Three major validity scores and the ten usual clinical scores from the MMPI were used, and $t$-tests were run between the three EEG groups. No meaningful differences in MMPI scores were found.

The subjects were then divided into those judged, on clinical grounds, to be "aggressive" or not, and who exhibited 14 and $6 / \mathrm{sec}$ positive spikes or not. The thirteen MMPI variables were again subjected to r-tests between these regrouped subjects. No meaningful MMPI differences related to EEG categorization were found, although MMPI differences between "aggressive" and "non-aggressive" patients were demonstrated.

Another group of patients $(N=33)$, all with 14 and 6/sec positive spikes, was compared with the three previously studied groups with respect to the thirteen MMPI variables. No meaningful differences were found: in fact, the greatest differences were those found when the new and the earlier " 14 and 6" groups were compared.

Claims for explicit personality characteristics of patients with 14 and $6 / \mathrm{sec}$ positive spikes seemingly must cuntinue to rest on impressionistic grounds.
57. "Electroencephalographic age" versus conceptral age of premature and full-term infants, - R. Engel and B, V. Butier (Portland, Ore.).

Of 1,000 newborn infants tested, 175 were considered premature according to our best obstetrical and pediatric judgment. In our series, $74.5 \%$ responded well to photic stimulation so that latency measurements of the evoked response in the occipital area could be made on inspection. An electrical response remained undetected in the background activity in $9.7 \%$ of all infants in the presence of a definite reaction to light by blinking or jerking. The response latency after a single flash was measured from the first deviation from the baseline caused by the superimposed signal to the first deviation caused by the response sequence.

The latency measurements are inversely proportional to the maturational state of the newborn. Full-term infants, 40 weeks of conceptual age at the time of testing, have a mean latency of $153 \pm 27 \mathrm{msec}$; premature babies, 200 msec and longer; postmature babies, sometimes 100 msec and less. Marked individual differences, independent of the great variations in birthweight, were noted in latency measurements, but tiue overall picture showed a progressive shortening of response latency between 29 and 46 weeks of conceptual age.

The "electroencephalographic age" at birth, according to pattern and response latency after photic stimulation, represents an independent measuring tool of the maturational stage at birth.

(Supported by USPHS Grants NB-2370 and NB-3166, NINDB).

\section{PRESIDENTIAL ADDRESS}

\section{Slow waves and neuronal setivity. -. C. Ajmone Marain (Betheeda, Md.).}

The findings obtained with intra- or excracellular and simultaneous gross electrode recording, 'which might have some bearing on the relationship between unit behavior and spontaneous or induced EEO patterns ("slow waves"), are analyzed.

The various reports on the subject are somewhat contradictory. Yet, in most instances in which the two phenomena are scemingly independent, critical evaluation would indicate that such "negative" findings cainot be taken as evidence that the phenomena are truly unrelated; rather they could be rationally accounted for by one of the following factors: (a) neuronal injury (unphysiological fring due to unrecognized, mild neuronal damage); (b) topographical factors (the neuron under study is not within the ill-definable area from where the slow wave appears to originate); (c) functional factors (the elements within a given area do not all behave in a grossly indiscriminate fashion); (d) simply quantitative factors and/or unrecognized technical limitations which might result in an apparent "absence" of spikes with preservation of slow waves.

Evidence for positive relationship between the two events is abundantly available and only its degreo varies depending on how clearly definable is the physiognomy of the slow phenomena. Such relationship increases progressively from spontaneous, irregular low voltage ac. tivity through organized spindle formations to evoked potentials, and is maximal for paroxysmal isolated transients.

It should thus be possible to state that slow waves and unitary activity are indeed closely related; furthermore, since the functional significance of action potentials is well established, we could now accept with greater confldence the concept of the former being an expression of (cerebral) neuronal activity; other, and particularly intracellular data would suggest that the slow waves actually refect changes in the activity of the neuronal population.

The same findings also provide some information about one aspect of the intrinsic nature of the slow waves, themselves. Assuming that these (be they spontaneous or evoked) are the expression of composite "synchronized" activities of a number of elements, the actual type of such elementary activities remains to be established. Among these, unitary spikes are the most easily (and, in extracellular tracing, exclusively) assessable. The temporal relationship between spikes and slow waves is highly suggestive but seldom absolute and because of the individ- 
ual brief duration of the former, a very critical degree of synchronization and a number of other assumptions would be necessary if they were solely or primarily responsible for occurrence and form of the recorded slow potential. Looking, for alternative interpretations, at the other cellular events, the available data support the original hypoth- esis of Eccles (1951) and suggest that the slower, graded phenomena represented by the two main types of synaptic potentials have a closer similarity and temporal relationship with the slow waves and that their synchronized occurrence is the most likely functional substrate for the latter.

\title{
SYMPOSIUM
}

\section{WHAT DO BRAIN WAVES TELL THE BRAIN?}

\author{
Chairman: D. P. Purpura (New York, N.Y.)
}

\section{Intracellular activities of thalamic and cortical neurons and evoked potentials. - D. P. Purpurn (New York, N, Y.).}

Intracellular recordings from thalamic and cortical neurons during medial (CM) and lateral (VL) thalamic stimulation in encéphale isole cats has provided information on three problems relevant to the analysis of brain waves: (1) the role of postsynaptic potentials (PSPs) in the production of dilterent components of evoked activities, (2) the manner in which different types of inputs to cortical neurons are refiested in different patterns of PSPs, and (3) the contributions of EPSP.IPSP sequences in thalamic neurons to the mechanism of EEG synchronization and desynchronization.

1. Injection of hyperpolarizing current pulses through recording electrodes in neurons in motor cortex has per. mitted dissociation of spikes and their sequelao from mem. brane potential changes evoked by VL or CM atimulation. Symaptic depolarizations observed during augmenting of recruiting responses were enhanced, whereas evoked hyperpolarizing potentials were inverted to depolarizing potentials during induced membrane hyperpolnrization. These results are similar to those oxpected following changes in resting membrane potential relative to the auilibrium potentials for ionic movements generating EPSPs and IPSPy, respectively. Complex tomporal sequences of EPSPs und IPSPs have been recorded during different components of cortical surface augmenting and recruiting responses. The data establish that PSPs are responsible for the major transmenbrane potential changes involved in the production of evoked cortical potentials.

2. Analysis of the time course and magnitude of PSPs evoked in cortical neurons during VL and CM stimulation, as well as observations on the effects of injected hyperpolarizing currents on PSPs, indicate that specific activation of cortical neurons occurs predominantly via synapses which are on or close to the soma, whereas activation of cortical neurons via nonspecific projections occurs both at sites close to the soma as well as remote from the membrane potential changes produced by injected hyperpolarizing currents. Failure to detect intermediary processes between PSPs and spikes following either mode of activation of cortical neurons is consistent with the view that graded responses referable to dendritic activities are PSPs. In the analysis of the origin and nature of different components of evoked cortical potentials particular emphasis is to be placed on findings of relatively stable and reproducible patterns of evoked PSPs in differing groups of neurons during a particular stage in the dispersion of synaptic activity in cortex.

3. Intracellular studies of the organization of intrathalamic synaptic pathways involved in EEG synchronization and EEG desynchronization elicited by low and high frequency stimulation, respectively, of midline thalamic structures have indicated that elements involved in the production of recruiting responses also participate in the effects of reticulocortical activation. Synchronization of thalamic neuronal discharge is affected by the development of stereotyped patterns of EPSP.IPSP sequences with an overall duration of $100-200 \mathrm{msec}$. Long latency prolonged IPSPs evoked in thalamic neurons during low frequency $\mathrm{CM}$ stimulation represent the major synuptic ovent underlying synchronization of thalamic neuronal activity. The transition from low to high frequency midlino stimuiation is associated with blockade of IPSP in thalamic neurons and enhancentent of excitatory synaptic drives which persist beyond the period of atimulation.

\section{Variations of cortical potentials with polarivation. - W. M. Landau (St, Louis, MO.).}

A preliminary report of this work appears in Trans. Amer. neurol. Ass., 1962, 87: 72-75. A ruller version will be published soon.

\section{Some prellminary observations on evoked responeses and perception of visual stimull in man. $-J, S$. Barlow (Boston, Mass.).}

Although many aspects of the interrelationships between brain waves and brain function have been studied in animals with the aid of experiments on learning and conditioning, this interrelationship has been less fully explored in man. However, experiments concerned with the study of the time course of perception of stimuli are severely limited in their applicability to animals because of the fact that the Jatter can signal the perception of a sensory stimulus only by a motor response (e.g., a conditional response). The exact time interval between the 